\title{
Silica-based aerogels as adsorbents for phenol-derivative compounds
}

\section{Telma Matias ${ }^{\mathrm{a}}$, Joana Marques ${ }^{\mathrm{a}}$, Margarida J. Quina ${ }^{\mathrm{a}}$, Licínio Gando-Ferreira ${ }^{\mathrm{a}}$, Artur J.M. Valente ${ }^{\mathrm{b}}$, António Portugal ${ }^{\mathrm{a}}$, Luísa Durães ${ }^{\mathrm{a}, *}$}

a CIEPQPF, Department of Chemical Engineering, University of Coimbra, Rua Sílvio Lima, 3030-790 Coimbra, Portugal

b Department of Chemistry, University of Coimbra, Rua Larga, 3004-535 Coimbra, Portugal

\section{H I G H L I G H T S}

- Highly porous silica-based aerogels with tailored degrees of hydrophobicity.

- Adsorbents with promising removal capacity for several phenol-derivatives.

- Pseudo-second order kinetics and Langmuir form isotherm for adsorption of SDBS

- Important role of the hydrophobic interactions in the adsorption process.

- Increased adsorption of 4chlorophenol exhibited by aerogels with $\beta$-cyclodextrin.

\section{A R T I C L E I N F O}

\section{Article history:}

Received 5 August 2014

Received in revised form 19 January 2015

Accepted 21 January 2015

Available online 7 February 2015

\section{Keywords:}

Adsorption

Silica-based aerogels

Phenolic compounds

Silica functionalization

Chemical interactions

$\beta$-Cyclodextrin
G R A P H I C A L A B S T R A C T

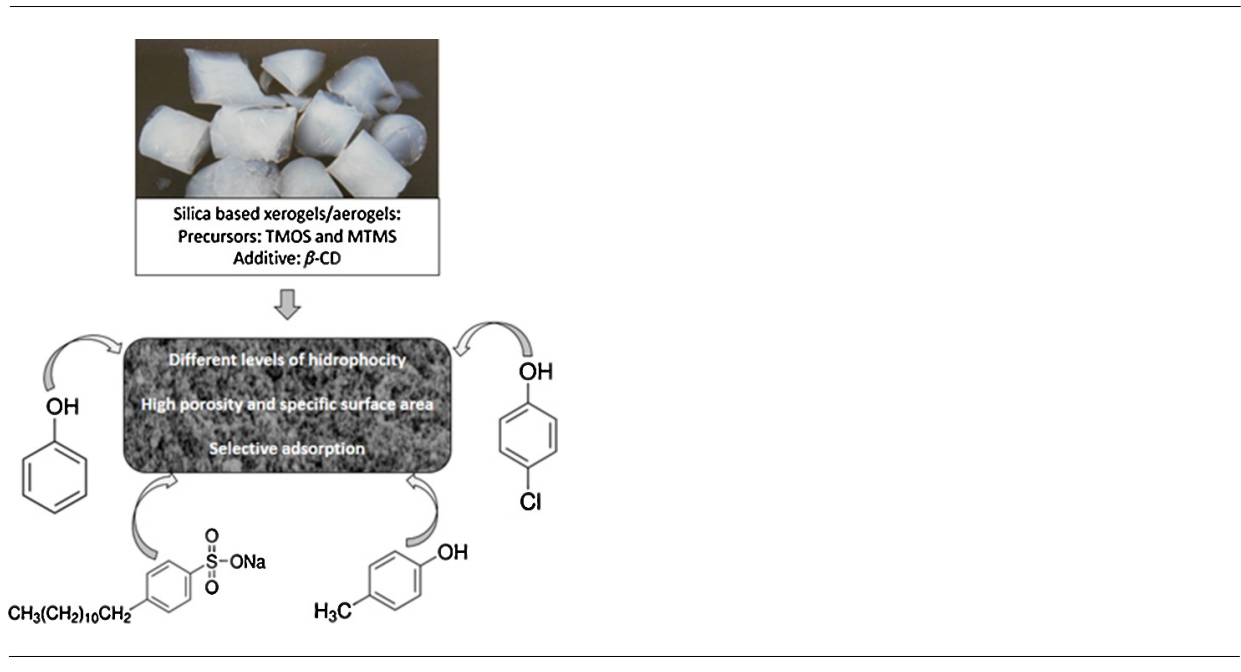

\section{A B S T R A C T}

The simultaneous presence of hydrophobic and hydrophilic chemical moieties in phenolic compounds imply some challenges in the choice of the more selective absorbent for their removal from industrial wastewaters. In this work, the adsorption capacities of chemically tailored aerogels/xerogels towards several phenolic compounds - phenol, $p$-cresol and 4-clorophenol - were evaluated to study the various kinds of interactions in the adsorption process as a function of the functional groups in the gel structure. The surfactant sodium dodecylbenzenesulfonate (SDBS) was also tested as an adsorbate due to its amphiphilic character. Highly porous silica-based aerogels/xerogels with different degrees of hydrophobicity/hydrophilicity were synthesized, by using a combination of methyltrimethoxysilane (MTMS) and tetramethyl orthosilicate (TMOS) precursors in different proportions, in order to provide a variable number of methyl and hydroxyl groups in the aerogels structure. $\beta$-cyclodextrin functionalization of the aerogels was also tested due to the recognized suitability of this macrocycle cavity for phenol retention. In this way, a systematic and innovative study was carried out based on a wide range of contact angles of the adsorbent matrices and different hydrophobic/hydrophilic nature of adsorbates, in order to have an increased understanding of the dominant adsorption interactions of phenolic compounds with these silica-based adsorbents. The sol-gel synthesis followed a one-step $\mathrm{NH}_{4} \mathrm{OH}$-catalyzed procedure and the drying of the gels was accomplished by supercritical fluid drying/extraction with $\mathrm{CO}_{2}$, to obtain aerogels, and evaporative drying, to produce xerogels. When using SDBS as adsorbate in the xerogels with intermediate wetting behaviour, good adsorption capacity is achieved and the adsorption

\footnotetext{
* Corresponding author. Tel.: +351 239798737; fax: +351 239798703.

E-mail address: luisa@eq.uc.pt (L. Durães).
} 
kinetics is well described by a pseudo-second order model. The aerogels with intermediate and high contact angles show higher adsorption capacities, with favourable isotherms, for the phenolic compounds with higher hydrophobicity, which shows the important role of hydrophobic interactions in this process. The best results were obtained for the aerogel functionalized with $\beta$-cyclodextrin when adsorbing the 4-chlorophenol, proving the positive effect of the presence of the $\beta$-cyclodextrin hydrophobic cavity in the adsorption of this highly hydrophobic pollutant.

(c) 2015 Elsevier B.V. All rights reserved.

\section{Introduction}

The presence of phenolic compounds in many industrial wastewaters, such as from petrochemical, pharmaceutical/cosmetics, polymers, paints/dyes, cork and textiles industries, among others, is of concern in terms of environmental/human health protection. Even in low concentrations, these compounds present high toxicity and low biodegradability and, as they also exhibit high volatility, they easily spread and migrate. More complex structures (higher degree of substitution in the aromatic ring) usually give rise to increased toxicity (e.g., alkylphenols, chlorophenols, bisphenol-A). The removal of phenolic compounds from wastewaters is also crucial to comply with the International Legislation, being their adsorption a conventional and effective route for industrial effluents, usually using activated carbon [1-3]. Adsorbents with high selectivity and adsorption capacity are needed, and the silica-based aerogels are promising materials and have attracted great interest for this purpose due to their extremely high porosity/surface area, chemical versatility and possibility of reutilization [4-7].

As the phenolic compounds have functional groups of hydrophobic and hydrophilic character, several types of interactions with the adsorbents are expected, namely hydrogen bonding, hydrophobic and electrostatic interactions, being these interactions also dependent on the $\mathrm{pH}$ of the solution, in particular the latter one [8-11]. Thus, an improved adsorption may be achieved by tailoring the aerogels surface chemistry. In addition, the aerogels characteristic extensive network of micro and mesopores [6] greatly favours the adsorption process.

The tailoring of the chemistry of silica-based aerogels may be performed by the co-precursor method [6,12], by cocondensation of silica precursors that give rise to inherently hydrophilic silicas, such as tetramethylorthosilicate (TMOS) and tetraethylorthosilicate (TEOS), with organosilanes that offer the possibility of compounding the silica network with hydrophobic groups. Examples of the later are alkyltrialkoxysilanes, such as methyltrimethoxysilane (MTMS), methyltriethoxysilane (MTES), vinyltriethoxysilane (VTES), and many others. Another possible method is the surface modification/derivatization of the gel $[6,12]$, in which the silica native gel (hydrophilic) is obtained first and then kept in a bath containing a mixture of solvent and surface modifying agent/silylating agent (usually organosilanes) that will condensate in the gel surface. In this method, the mass transfer in the gel takes place by diffusion only. Therefore, large amounts of solvent and significant time are required to achieve solvent exchange and subsequent surface modification, respectively, being thus very costly.

Regarding to the adsorption of phenolic compounds on silicabased materials, including aerogels/xerogels, only a few studies were found in the literature. Wu et al. [9-11] compared the adsorption of organic dyes (alizarin and phenol red) on several xerogels, synthesized by the co-precursor approach combining TEOS with several triethoxysilanes and, also, with bis(trimethoxysilyl)hexane (BTMSH) and bis(trimethoxysilylpropyl)amine (BTMSPA). They concluded that the organic dyes adsorption in the xerogels is influenced by all types of interactions referred above, but the hydrophobic interactions are of major relevance. The adsorption capacity of phenol red was the lowest among all the tested adsorbents (always below $45 \mathrm{mg} \mathrm{g}^{-1}$ ). You et al. [13] also tested a xerogel made from TEOS/BTMSH system, but for adsorption of bromophenol blue. The obtained adsorption capacity did not reach values above $20 \mathrm{mg} \mathrm{g}^{-1}$. Haghbeen and Legge [14] studied the combination of TMOS and TEOS with propyltrimethoxysilane (PTMS) and methyltripropoxysilane (MTPS) to produce xerogel adsorbents for many types of phenolic compounds, but the adsorption capacities were not provided.

Concerning the surface derivatization method, An et al. have tested silica particles as adsorbents of phenol after performing the grafting of polyethyleneimine (PEI) $[15,16]$ and polymethacrylic acid (PMAA) [8] onto the particles surface. They obtained a high adsorption capacity for phenol $\left(160 \mathrm{mg} \mathrm{g}^{-1}\right.$ and $163 \mathrm{mgg}^{-1}$ for PEI and PMAA, respectively) justified by the hydrogen bonding and electrostatic interactions. Faraji et al. [17,18] performed the modification of the surface of silica gel particles by compounding it with $\beta$-cyclodextrin, using the linking agent 3glycidoxypropyltrimethoxysilane, and tested this adsorbent for phenol and many phenolic compounds with different types of functional substituent groups in the aromatic ring. Although it was referred that good adsorption performance was achieved, no numeric data was provided. Qin et al. [7] have modified the surface of a TEOS-derived xerogel with TMCS and got an adsorption capacity of $142 \mathrm{mg} \mathrm{g}^{-1}$ for phenol. Finally, Anbia and co-workers $[19,20]$ had used mesoporous silica (MCM-41 and SBA-15) and made its surface derivatization with aminopropyltrimethoxysilane, in order to obtain better adsorption capacity for chlorophenols, bromophenols and iodophenols. They achieved very good adsorption performances and the best result was obtained for modified MCM-41, which showed an adsorption capacity of $339 \mathrm{mg} \mathrm{g}^{-1}$ for 2,4,6-trichlorophenol.

The literature results described above allow concluding that the hydrophobic/hydrophilic interactions between the silica-based adsorbent and the phenolic compounds are complex and very important to the adsorption capacity of the adsorbents. In an earlier work [4], we had tested MTMS-derived aerogels and xerogels, which were highly porous, flexible and hydrophobic [21-23], to the adsorption of the aromatic solvents benzene, toluene and phenol from water. The higher adsorption capacities were obtained for the aerogel in the cases of toluene $\left(173 \mathrm{mg} \mathrm{g}^{-1}\right)$ and benzene $\left(192 \mathrm{mg} \mathrm{g}^{-1}\right)$, which were remarkably high when compared to the available literature data. However, for phenol the adsorption performance was not the best. Thus, we have now focused on the chemical modification of the aerogels/xerogels obtained from MTMS, in order to improve their adsorption capacity towards phenolic compounds.

In this work, the co-precursor method is applied to obtain aerogels and xerogels of tailored hydrophobicity/hydrophilicity, by combining different proportions of MTMS and TMOS which contribute to have a balance of $-\mathrm{CH}_{3}$ and $-\mathrm{OH}$ in the final structure of the gel. In addition, $\beta$-cyclodextrin ( $\beta$-CD) was added along with the precursors to one of the formulations in order to create a dispersion of this macromolecule in the gel matrix. It is recognized that the hydrophobic hole of $\beta$-CD can act as a cage for the aromatic ring of phenol. With these chemically tailored materials, the aim is to 
investigate their adsorption interactions with three phenolic compounds, phenol, cresol and 4-chlorophenol, which show increasing hydrophobic character, and with one surfactant, SDBS, with a structure somewhat similar to phenolic compounds. Equilibrium and kinetic studies were carried out for this purpose. The understanding of the nature of dominant adsorption interactions of phenolic compounds with the adsorbents is a crucial step to design more selective materials for the specific moieties that these compounds can present.

\section{Materials and methods}

\subsection{Materials}

For the synthesis of aerogels/xerogels, TMOS $(\geq 98)$, MTMS ( $\geq 98 \%$ ), ammonium hydroxide $\left(25 \% \mathrm{NH}_{3}\right.$ in $\left.\mathrm{H}_{2} \mathrm{O}\right)$, methanol ( $\geq 99.8 \%, \mathrm{MeOH})$ and $\beta$-cyclodextrin $(\geq 97 \%, \beta$-CD) were purchased from Sigma-Aldrich. Ethanol ( $\geq 99.8 \%$, EtOH) was purchased from Fisher. All reagents were used without further purification.

To prepare the synthetic effluents of this work, analytical grade phenol (99\%), p-cresol (99\%), 4-chlorophenol (99\%) and sodium dodecylbenzenesulfonate (80\%, SDBS) were obtained from Aldrich. Deionised water of high purity (from a Milipore ultra-pore water system) was used.

The structures and some chemical properties of the used precursors/additives, selected pollutants and SDBS are present in Table 1.

Before the adsorption tests, both aerogels and xerogels adsorbents were ground and passed through two sieves to retain the particle sizes in the interval $74-250 \mu \mathrm{m}$.

\subsection{Synthesis of adapted silica-based aerogels and xerogels}

\subsubsection{Aerogels/xerogels synthesized from TMOS-MTMS chemical system}

MTMS and TMOS precursors were diluted in $\mathrm{MeOH}$ and a basic solution of $\mathrm{NH}_{4} \mathrm{OH}(1 \mathrm{M})$ was added. The mixture was stirred during $10 \mathrm{~min}$ and the resultant sol was transferred to plastic syringes and aged during five days at $27^{\circ} \mathrm{C}$. The molar ratios of the system components were: MTMS:TMOS - (0.2-0.8) to (0.8-0.2); $\mathrm{Si}: \mathrm{MeOH}-12 ; \mathrm{Si}: \mathrm{H}_{2} \mathrm{O}-4$. The obtained gels were dried by two drying methods: ambient pressure drying (APD) and supercritical fluids extraction (SFE). The APD method consists in subjecting the samples to several temperature cycles in an oven. The used temperatures were $60^{\circ} \mathrm{C}(24 \mathrm{~h}), 100^{\circ} \mathrm{C}(1 \mathrm{~h}), 150^{\circ} \mathrm{C}(1 \mathrm{~h})$ and $200^{\circ} \mathrm{C}(1 \mathrm{~h})$. In the SFE method, the gel was firstly washed with the solvent and, then, a continuous flow of supercritical $\mathrm{CO}_{2}$ was passed in the sample to promote its drying.

\subsubsection{Aerogels synthesized from TMOS-MTMS- $\beta-C D$ chemical system}

The synthesis of the aerogels with $\beta$-CD was slightly different than described in Section 2.2.1, in order to overcome the $\beta$-CD solubility limitation. Initially $0.18 \mathrm{~g}$ of $\beta$-CD was dissolved in a solution containing a solvent mixture of $\mathrm{H}_{2} \mathrm{O}, \mathrm{EtOH}(1: 2.3 \mathrm{v} / \mathrm{v})$ and $\mathrm{NH}_{4} \mathrm{OH}$. Then the precursors (TMOS and MTMS) were added and the resultant solution was stirred during $10 \mathrm{~min}$ and kept in an oven at $27^{\circ} \mathrm{C}$, during 5 days, for gelation. The used drying method was SFE, already described in Section 2.2.1. The molar ratios of

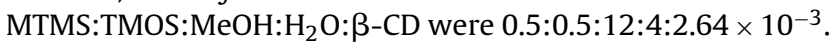

For simplicity, the aerogels and xerogels of this work were identified by a short designation, as described in the following two examples. Sample A-50M50T-CD corresponds to an Aerogel (A), with $50 \%$ of the Si from MTMS (50M) and 50\% of the Si from TMOS (50T), and $\beta$-CD was added in the system (CD); sample X-50M50T means that it is a xerogel (X), with $50 \%$ of the Si from both MTMS (50M) and TMOS (50T).

\subsection{Aerogels/xerogels characterization methods}

\subsubsection{FTIR spectroscopy}

FTIR spectroscopy was performed on a Jasco FT/IR 4200 spectrometer. The spectra were obtained in the $\mathrm{KBr}$ mode, using $\mathrm{KBr}$ pellets composed by $80 \mathrm{mg}$ of $\mathrm{KBr}$ and $0.2-0.3 \mathrm{mg}$ of aero$\mathrm{gel} / \mathrm{xerogel}$, in a wave number range of $400-4000 \mathrm{~cm}^{-1}$.

\subsubsection{Contact angle measurement}

The contact angle of the materials was obtained by dropping water droplets on the surface of pre-compressed pellets of aerogel/xerogel, in order to obtain the hydrophobicity/hydrophilicity level of each sample. The used equipment and software for the contact angle evaluation was from Dataphysics, model OCA 20.

\subsubsection{Bulk and skeletal densities evaluation}

By helium picnometry (Micromeritics, Accupyc 1330), it was possible to measure the skeletal density of the aerogels/xerogels, which along with the bulk density allows obtaining the porosity of the materials. The bulk density was obtained by weighting the samples and measuring their volume by immersion in ethanol.

\subsubsection{Scanning electron microscopy}

The microstructure of the aerogels/xerogels was observed by scanning electron microscopy (SEM), using a microscope from $J O E L$, model JMS-5310. The samples were previously coated with gold to overcome their low electric conductivity.

\subsubsection{Surface area evaluation and porosimetry}

The specific surface area and pore size distribution/average pore size were obtained by nitrogen gas adsorption, with the BET adsorption theory and the BJH desorption method, respectively, and using ASAP 2000 equipment, from Micromeritics. Previous degasification of the samples was performed in a vacuum oven at $50^{\circ} \mathrm{C}$, during 3 days, and also in the equipment.

\subsubsection{Simultaneous differential thermal analysis}

A Simultaneous Differential Thermal Analyzer (DSC/TGA), model SDT Q500, from TA Instruments, was used to observe the thermal behaviour of the aerogels and to obtain confirmation of the presence of $\beta$-CD in the samples. The samples were placed in an alumina pan and heated from room temperature to $1200^{\circ} \mathrm{C}$, at a constant heating rate of $10^{\circ} \mathrm{C} / \mathrm{min}$, under a nitrogen flow.

\subsection{Adsorption tests with SDBS and phenolic compounds}

Concentrations of SDBS and phenolic compounds were determined by using the UV-Vis spectrophotometer T70, from PG Instruments. The concentrations used in the calibration curves were in the range of $1-60 \mathrm{mg} \mathrm{L}^{-1}$ for phenol and $p$-cresol, $1-20 \mathrm{mg} \mathrm{L}^{-1}$ for 4-chlorophenol and $0.5-40 \mathrm{mg} \mathrm{L}^{-1}$ for SDBS. The solutions were analyzed by measuring the absorbance at $270 \mathrm{~nm}$ (phenol), $276 \mathrm{~nm}$ (p-cresol), $280 \mathrm{~nm}$ (4-chlorophenol) and $222 \mathrm{~nm}$ (SDBS). Quartz glass cells (Hellma) of $10 \mathrm{~mm}$ path length were used.

\subsubsection{Adsorption equilibrium and kinetics}

Equilibrium isotherms for the system X-50M50T/SDBS were determined through batch tests, where $45 \mathrm{~mL}$ of SDBS solutions with several concentrations $(87,174,348,1742,3485$ and $\left.6970 \mathrm{mg} \mathrm{L}^{-1}\right)$ were added into glass bottles $(50 \mathrm{~mL})$ containing an appropriate amount of adsorbent $(0.09 \mathrm{~g})$. These flasks were agitated at $16 \mathrm{rpm}$ in a shaker (Heidolph - REAX 20) at room temperature, and samples for analysis were withdrawn after $24 \mathrm{~h}$ of 
Table 1

Properties of selected precursors and phenol-derivative compounds.

\begin{tabular}{|c|c|c|c|c|}
\hline \multicolumn{5}{|l|}{ Precursors/additives } \\
\hline Compound & Chemical structure & $\operatorname{MW}\left(\mathrm{g} \mathrm{mol}^{-1}\right)$ & $S\left(\mathrm{H}_{2} \mathrm{O}\right)^{\mathrm{a}}\left(\mathrm{g} \mathrm{L}^{-1}\right)[24]$ & $\log P_{\text {ow }}{ }^{b}$ \\
\hline Methyltrimehoxysilane (MTMS) & $\mathrm{OCH}_{3}$ & 136.22 & 80; hydrolysis & $0.7[24]$ \\
\hline Tetramethyl orthosilicate (TMOS) & & 152.22 & $\begin{array}{l}\text { Hydrolysis; soluble in } \\
\text { organic solvents }\end{array}$ & - \\
\hline$\beta$-Cyclodextrin $(\beta$-CD) & & 1134.98 & 14.3 & - \\
\hline
\end{tabular}

Phenol-derivative compounds

\begin{tabular}{|c|c|c|c|c|c|}
\hline Compound & Chemical structure & $\mathrm{MW}\left(\mathrm{g} \mathrm{mol}^{-1}\right)$ & $S\left(\mathrm{H}_{2} \mathrm{O}\right)^{\mathrm{c}}\left(\mathrm{g} \mathrm{L}^{-1}\right)[25]$ & $\log P_{\text {ow }}{ }^{b}$ & $\mathrm{LD}_{50}$ (rats) $\left(\mathrm{mgg}^{-1}\right)[24]$ \\
\hline Phenol & & 94.11 & 94.8 & $1.5[25]$ & 317 \\
\hline$p$-Cresol & & 104.14 & 21.52 & $1.9[26]$ & 207 \\
\hline 4-Chlorophenol & & 128.56 & 28 & $2.4[26]$ & 670 \\
\hline $\begin{array}{l}\text { Sodium dodecylbenzene } \\
\text { sulfonate (SDBS) }\end{array}$ & & 348.48 & 200 & $0.45[27]$ & 438 \\
\hline
\end{tabular}

a Solubility in water at $20^{\circ} \mathrm{C}$.

b $\log _{10}$ partition coefficient $n$-octanol/water at $25^{\circ} \mathrm{C}$.

c Solubility in water at $25^{\circ} \mathrm{C}$.

d Critical micelle concentration (CMC) is $1.2 \times 10^{-3} \mathrm{M}\left(418.2 \mathrm{~g} \mathrm{~L}^{-1}\right)$ [28].

contact time in order to determine the concentration of SDBS present in solution.

Equilibrium adsorption curves of phenol, $p$-cresol and 4chlorophenol onto X-50M50T, A-20M80T, A-50M50T, A-80M20T and A-50M50T-CD aerogels/xerogels were obtained by following the same procedure, but with different initial concentrations of adsorbate, varying between 10 and $1000 \mathrm{mg} \mathrm{L}^{-1}$. For each concentration of adsorbate (SDBS or phenolic compounds), two replicas were prepared.

The adsorbate uptake $\left(q_{\mathrm{e}}\right)$, expressed as adsorbate removal per unit mass of adsorbent ( $\mathrm{mg} \mathrm{g}^{-1}$ ), was calculated according to Eq. (1), where $C_{0}$ is the initial adsorbate concentration $\left(\mathrm{mg} \mathrm{L}^{-1}\right), C_{\mathrm{e}}$ the equilibrium concentration ( $\left.\mathrm{mg} \mathrm{L}^{-1}\right), V$ the batch volume (L) and $m$ the adsorbent mass $(\mathrm{g})$. The percentage of adsorbate removed from the aqueous solution was calculated using Eq. (2), where $C_{0}$ $\left(\mathrm{mg} \mathrm{L}^{-1}\right)$ and $C_{\mathrm{e}}\left(\mathrm{mg} \mathrm{L}^{-1}\right)$ are the initial and equilibrium adsorbate concentrations, respectively.
$q_{e}=\frac{\left(C_{0}-C_{e}\right) V}{m}$

$R(\%)=\frac{C_{0}-C_{e}}{C_{0}} \times 100$

Preliminary kinetic tests were carried out in order to determine the minimum contact time to establish equilibrium conditions between X-50M50T and SDBS. In these tests, $0.09 \mathrm{~g}$ of adsorbent and $45 \mathrm{~mL}$ of adsorbate solution with initial concentration $200 \mathrm{mg} \mathrm{L}^{-1}$ were poured into $50 \mathrm{~mL}$ flasks. These experiments were carried out under the same conditions as those used in the adsorption equilibrium experiments (temperature and agitation), and samples for analysis were collected after a certain contact time that varied between 5 and $1440 \mathrm{~min}$. After establishing the contact time (360 min), experiments were performed in order to determine the SDBS uptake along time, varying the feed solution concentrations 
$\left(11,22,44\right.$ and $\left.87 \mathrm{mg} \mathrm{L}^{-1}\right)$ at some conditions of temperature, adsorbent amount and adsorbate volume described above.

\subsubsection{Kinetic models}

The kinetics of SDBS adsorption was evaluated applying two different models: (1) the pseudo-first-order kinetic model [29], and (2) pseudo-second-order kinetic model [30].

The linear form of the equation for the pseudo-first-order is expressed as:

$\ln \left(q_{e}-q_{t}\right)=\ln \left(q_{e}\right)-k_{1} t$

where $q_{\mathrm{e}}$ and $q_{t}$ are the amounts of SDBS adsorbed on the adsorbent $\left(\mathrm{mg} \mathrm{g}^{-1}\right)$ at equilibrium and at time $t$, respectively, and $k_{1}$ is the Lagergren pseudo-first order adsorption rate constant $\left(\mathrm{min}^{-1}\right)$.

The linear form of the pseudo-second-order model is written as:

$\frac{t}{q_{t}}=\frac{1}{k_{2} \cdot q_{e}^{2}}+\frac{1}{q_{e}} \cdot t$

where $k_{2}$ is the second-order adsorption rate constant ( $\mathrm{g} \mathrm{mg}^{-1} \mathrm{~min}^{-1}$ ).

\subsubsection{Adsorption isotherm models}

The data correlation either using theoretical or empirical models is essential for the interpretation of experimental adsorption isotherms. The determination of the adsorption capacity at various equilibrium concentrations $\left(C_{\mathrm{e}}\right)$ was performed by obtaining the experimental adsorption isotherm. The commonly used Langmuir and/or Freundlich models were fitted to the experimental data. These models are given by Eqs. (5) and (6), respectively.

$q_{e}=\frac{q_{\max } K C_{e}}{1+K C_{e}}$

$q_{e}=K_{F} \cdot C_{e}^{1 / n}$

Langmuir parameters $q_{\max }\left(\mathrm{mg} \mathrm{L}^{-1}\right)$ and $K\left(\mathrm{mg} \mathrm{L}^{-1}\right)$ of Eq. (5) are the maximum capacity of adsorption at high equilibrium concentrations (monolayer of adsobate) and the equilibrium constant, respectively. The parameters $K_{\mathrm{F}}\left(\mathrm{mg} \mathrm{g}^{-1}\left(\mathrm{mg} \mathrm{L}^{-1}\right)^{1 / n}\right)$ and $1 / n$ of Eq. (6) are the Freundlich capacity factor and the Freundlich intensity parameter, respectively [31]. The concentration of adsorbate retained in the adsorbent phase, $q_{\mathrm{e}}\left(\mathrm{mg} \mathrm{g}^{-1}\right)$, and the percentage of adsorbate removed from aqueous solution were calculated by Eqs. (1) and (2) defined in Section 2.4.1.

\section{Results and discussion}

\subsection{Adsorbents characterization}

\subsubsection{Chemical structure and hydrophilicity/hydrophobicity of} the adsorbents

Fig. 1 presents the FTIR spectra of the xerogel and aerogels synthesized with the system MTMS-TMOS. The ascribing of the vibration bands to the chemical bonds, also presented in this figure, considered the characteristic vibration frequencies of organic and silica-based materials published in the literature [32,33].

The characteristic broad band/double band due to the asymmetric stretching vibrations of siloxane bonds ( $\mathrm{Si}-\mathrm{O}-\mathrm{Si}$ ) appears at $\sim 1100 \mathrm{~cm}^{-1}$ and $\sim 1270 \mathrm{~cm}^{-1}$, and the double band seen for the sample A-80M20T transforms gradually in a larger band with a shoulder (less defined band at $1270 \mathrm{~cm}^{-1}$ ) with the increasing amount of TMOS in the precursor system. This was expected, as the pattern observed for the sample A-20M80T is similar to those obtained for native silica aerogels, which exhibit a higher degree of structural order when compared to MTMS-derived aerogels. The symmetric stretching vibrations of the same bonds are observed in the sharp peak near $780 \mathrm{~cm}^{-1}$, and this peak become broader, less

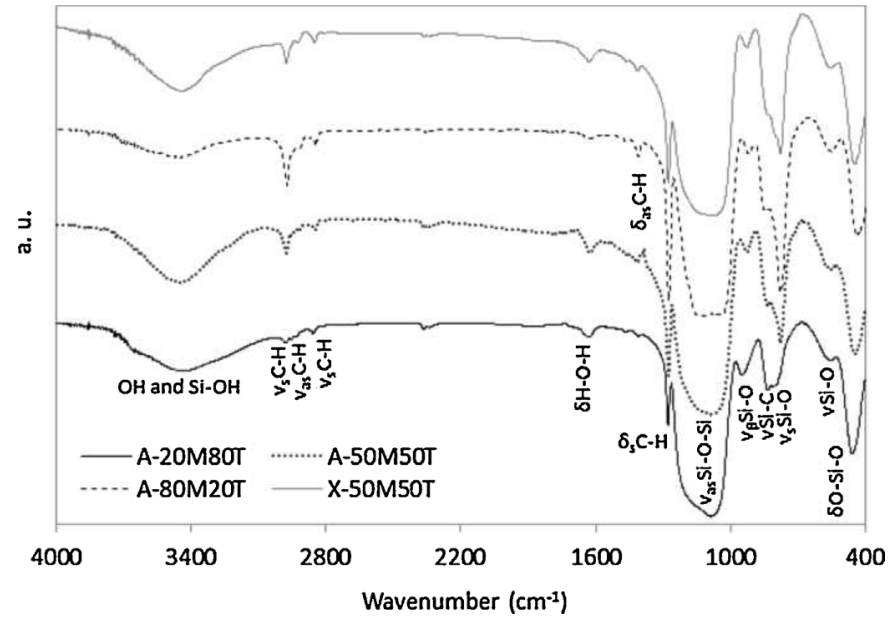

Fig. 1. FTIR spectra for MTMS-TMOS-derived xerogel and aerogels $(v$, stretching vibration; $v_{\mathrm{s}}$, symmetric stretching vibration; $v_{\text {as }}$, asymmetric stretching vibration; $\delta$, deformation vibration; $\delta_{s}$, symmetric deformation vibration; $\delta_{\text {as }}$, asymmetric deformation vibration (bending); $v_{\beta}$, in plane-stretching vibration).

intense and shifts to higher wavenumbers with increasing amount of TMOS. Finally, the peak corresponding to the deformation vibration of $\mathrm{O}-\mathrm{Si}-\mathrm{O}$ bonds appears around $450 \mathrm{~cm}^{-1}$; the small broad bands seen at $920-950 \mathrm{~cm}^{-1}$ and at $550 \mathrm{~cm}^{-1}$ are related to the stretching vibrations in-plane of $\mathrm{Si}-\mathrm{O}$ bonds and to the stretching vibrations of the same bonds in silica defects, respectively.

The stretching vibrations of $\mathrm{Si}-\mathrm{C}$ bonds appear at $\sim 840 \mathrm{~cm}^{-1}$ and become less intense with a smaller amount of MTMS in the precursor system, as expected. The symmetric and asymmetric stretching vibrations of the $\mathrm{C}-\mathrm{H}$ bonds of the $-\mathrm{CH}_{3}$ groups linked to $\mathrm{Si}$ show between 2840 and $3000 \mathrm{~cm}^{-1}$, also vanishing with decreasing amount of MTMS. The symmetric deformation vibrations of the $\mathrm{C}-\mathrm{H}$ bonds are visible in the sharp peak at $1410 \mathrm{~cm}^{-1}$, being the asymmetric mode also observed, at $1460 \mathrm{~cm}^{-1}$.

Hydroxyl groups are also present in the structure, noted by the broad bands near $1625 \mathrm{~cm}^{-1}$ and in the range $3200-3600 \mathrm{~cm}^{-1}$, and these bands are more evident with high amounts of TMOS in the precursor system (samples A-50M50T and A-20M80T), which was also expected since TMOS gives rise to more $\mathrm{OH}$ terminal groups in the structure.

In summary, these spectra prove that obtained adsorbents are mainly composed by a silica backbone, with methyl groups linked to one part of the $\mathrm{Si}$ atoms and $\mathrm{OH}$ terminal groups. The chemical structure exhibited by the xerogel (X-50M50T) is similar to that of the aerogel counterpart. The structural order of the silica network increases with the relative amount of TMOS/MTMS, which is seen by the shifting and shape changing of some bands. The intensity of the $\mathrm{Si}-\mathrm{CH}_{3}$ and $\mathrm{Si}-\mathrm{OH}$ groups also changes with the proportion of the precursors, as expected, proving that the gels surface is being effectively modified by this precursor combination.

For the aerogel synthesized with $\beta$-CD, the characteristic FTIR peaks of this macromolecule are masked by the larger bands of silica until $1400 \mathrm{~cm}^{-1}$. Thus, it was decided to perform TGA, in order to confirm the presence of $\beta$-CD in the structure. The obtained TGA curves are presented in Fig. 2 . It is possible to verify that $\beta$-CD thermally decomposes between 314 and $332{ }^{\circ} \mathrm{C}$. For the sample A50M50T-CD a weight loss of $2.1 \%$ is observed in a similar interval (304-346 ${ }^{\circ} \mathrm{C}$ ), and this is certainly due to the decomposition of $\beta$-CD since it does not occur for the sample A-50M50T. The weight losses that starts at $370^{\circ} \mathrm{C}$ for samples A-50M50T and A-50M50T-CD are due to the decomposition of the methyl groups of the aerogels structure [23], a phenomenon that changes significantly the contact 


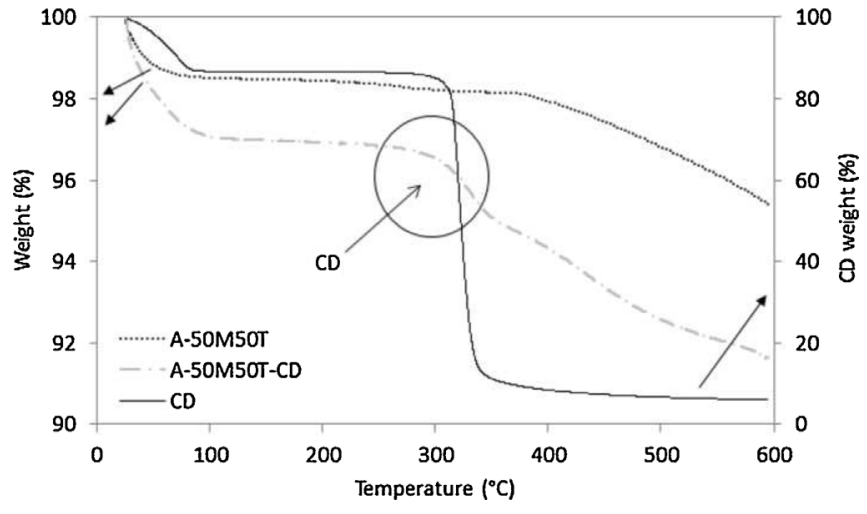

Fig. 2. Comparison of the TGA profiles for the samples A-50M50T, A-50M50T-CD and $\mathrm{CD}$.

angle of these samples, turning them hydrophilic. The weight losses below $100^{\circ} \mathrm{C}$ are justified by residual solvent/catalysts evaporation.

The contact angles of the synthesized adsorbents with water are given in Table 2. When the percentage of MTMS in the precursor system increases from 20 to $80 \%$ (decreasing the percentage of TMOS in the opposite sense), the contact angles of the aerogels vary from 29 to $125^{\circ}$, i.e. the material behaviour spans from hydrophilic to hydrophobic. The xerogel shows a slightly higher contact angle when compared to the equivalent aerogel. This may be explained by a different roughness of the xerogel surface originated by a denser porous network, as will be seen in the next section. The addition of $\beta$-CD induces a decrease in the contact angle, which can be explained by the additional $\mathrm{OH}$ groups of the macromolecule and, in addition, a possible incomplete condensation of silanols due to the presence of $\beta$-CD.

\subsubsection{Physical and structural characteristics of the adsorbents}

Table 2 presents the bulk densities of the obtained aerogels/xerogels, as well as their specific surface areas and average pore sizes. Fig. 3 shows their pore size distributions. It can be concluded that the aerogels bulk densities are between 200 and $350 \mathrm{~kg} \mathrm{~m}^{-3}$, which are typical values for aerogels containing orthosilicates [6,12]. The addition of $\beta$-CD does not change significantly the bulk density. For the xerogel, the bulk density is higher $\left(\sim 500 \mathrm{~kg} \mathrm{~m}^{-3}\right)$ and this was expected considering the higher capillary pressures developed during ambient pressure drying, which lead to gel shrinkage.

The specific surface areas of the materials are very high, almost always above $800 \mathrm{~m}^{2} \mathrm{~g}^{-1}$ (Table 2). In general, a lower bulk density leads to higher porosity and specific surface area, with the exception of the xerogel for which the higher surface area may be explained by the smaller pore sizes. In fact, it can be seen in Fig. 3 that the pore size distribution of the xerogel shifts to lower pore diameter (30-50 $\AA$ ), when compared to aerogels, and this can be explained again by the pore shrinkage during evaporative drying. In the case of aerogels, there are two regions of pore sizes with higher frequency: one between 60 and $110 \AA$, due to the contribution of TMOS in the network, and the other between 100 and $700 \AA$, explained by the contribution of MTMS (larger pores due to the steric hindrance resultant from the presence of the methyl groups). For all samples, the pore sizes are mainly in the mesopores range (20-500 $\AA$ ). As for density, the addition of $\beta$-CD does not seem to modify significantly the pore size distribution.

SEM micrographs of the obtained materials are presented in Fig. 4. They show very similar and more closed structures for the samples with a percentage of TMOS up to $50 \%$, with samples A20M80T and X-50M50T showing the densest appearance. Sample A-80M20T clearly has more large pores, in agreement with the pore size distribution results. All the adsorbents are formed by a 3-D solid network with very small interlinked units $(<1 \mu \mathrm{m})$.

\subsection{Adsorption equilibrium and kinetics of SDBS on the $X$-50M50T adsorbent}

Fig. 5 shows the effect of the initial concentration of SDBS on its adsorption kinetics on X-50M50T. In a first approach, it can be seen that both the amount of SDBS adsorbed by the xerogel and the required time to reach equilibrium increase by increasing the SDBS concentration. The later ranges from 60 to 120 min, when the concentration of SDBS changes from 11.0 to $87 \mathrm{mg} \mathrm{L}^{-1}$. It is known that achieving adsorption equilibrium in a short period of time suggests a physical adsorption mechanism, whilst a long range time suggests a chemical-based adsorption process or difficulty of accessing to adsorbent active sites by the adsorbate [34]. Fig. 6 shows representative plots of the fit of linearized forms of Eqs. (3) and (4) to experimental kinetics data. From this analysis, and from the analysis of fitting parameters resumed in Table 3, it can be seen that the pseudo-second order model shows better correlation coefficients. Both facts suggest that adsorption of SDBS by xerogel follows the pseudosecond order kinetic model, which relies on the assumption that a monolayer formation may be the rate-limiting step $[35,36]$, in agreement with the Langmuir sorption isotherms, as will be discussed below.

Rate constants, $k_{2}$, are of same order of magnitude than those found for similar systems [34] and the observed decrease by

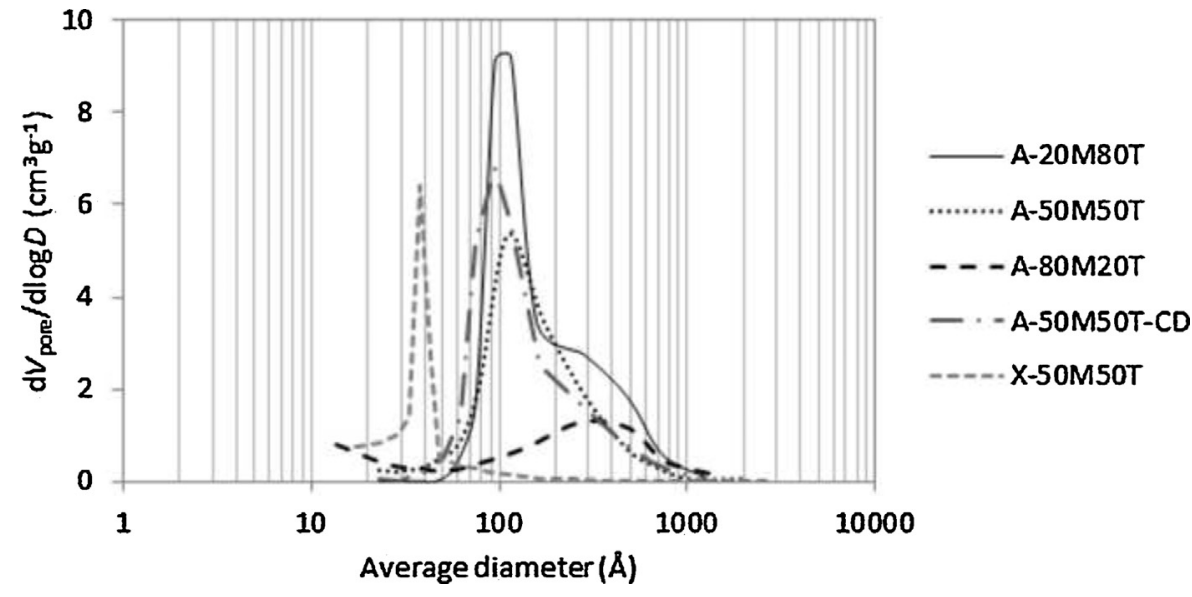

Fig. 3. Pore size distributions of the synthesized adsorbents. 
Table 2

Bulk density, contact angle, specific surface area and average pore size of the adsorbents.

\begin{tabular}{|c|c|c|c|c|}
\hline Sample & Bulk density $\left(\mathrm{kg} \mathrm{m}^{-3}\right)$ & Contact angle $\left(^{\circ}\right)$ & Specific surface area (BET) $\left(\mathrm{m}^{2} \mathrm{~g}^{-1}\right)$ & Pore size (BJH desorption) ( $\AA$ ) \\
\hline A-20M80T & 239 & $35 \pm 6$ & $843 \pm 3$ & 115 \\
\hline A-50M50T & 243 & $97 \pm 4$ & $888 \pm 3$ & 111 \\
\hline A-80M20T & 351 & $120 \pm 5$ & $655 \pm 2$ & 275 \\
\hline A-50M50T-CD & 297 & $61 \pm 13$ & $826 \pm 3$ & 94 \\
\hline $\mathrm{X}-50 \mathrm{M} 50 \mathrm{~T}$ & 523 & $107 \pm 4$ & $938 \pm 3$ & 38 \\
\hline
\end{tabular}
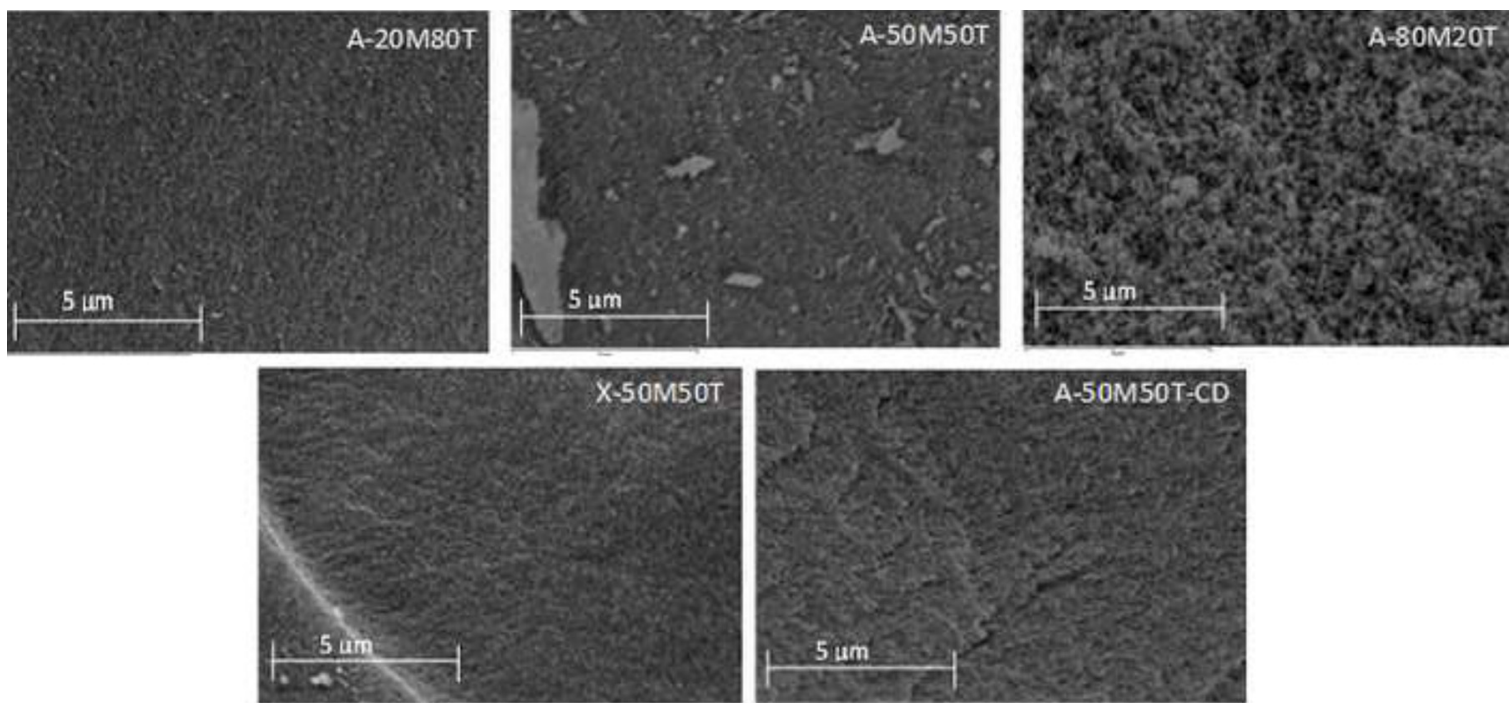

Fig. 4. SEM micrographs of the synthesized adsorbents.

Table 3

Kinetic parameters for the adsorption of SDBS on X-50M50T.

\begin{tabular}{|c|c|c|c|c|c|c|c|}
\hline \multirow[t]{2}{*}{$C_{0}\left(\mathrm{mg} \mathrm{L}^{-1}\right)$} & \multicolumn{3}{|c|}{ Pseudo-first order equation } & \multicolumn{3}{|c|}{ Pseudo-second order equation } & \multirow[b]{2}{*}{$q_{\mathrm{e}}(\exp )\left(\mathrm{mg} \mathrm{g}^{-1}\right)$} \\
\hline & $k_{1}\left(10^{-3} \mathrm{~min}^{-1}\right)$ & $q_{\mathrm{e}}\left(\mathrm{mgg}^{-1}\right)$ & $R^{2}$ & $k_{2}\left(10^{-2} \mathrm{ming} \mathrm{mg}^{-1}\right)$ & $q_{\mathrm{e}}\left(\mathrm{mg} \mathrm{g}^{-1}\right)$ & $R^{2}$ & \\
\hline 11 & $8 \pm 2$ & $1.5 \pm 0.2$ & 0.65228 & $2.1 \pm 0.1$ & $3.05 \pm 0.08$ & 0.99013 & 3.1 \\
\hline 22 & $9 \pm 1$ & $2.7 \pm 0.3$ & 0.81092 & $1.4 \pm 0.7$ & $6.0 \pm 0.1$ & 0.99576 & $5.7 \pm 0.2$ \\
\hline 44 & $9.9 \pm 0.9$ & $9.5 \pm 0.9$ & 0.92755 & $0.17 \pm 0.06$ & $12.1 \pm 0.5$ & 0.98524 & $10.6 \pm 0.5$ \\
\hline 87 & $17 \pm 1$ & $16 \pm 1$ & 0.90327 & $0.21 \pm 0.08$ & $22.5 \pm 0.5$ & 0.99391 & $21.1 \pm 0.7$ \\
\hline
\end{tabular}

increasing the initial concentration of SDBS is in agreement with the dependence of time needed to reach the adsorption equilibrium. It is also worth noticing that by increasing the initial concentration of SDBS to 44 and $87 \mathrm{mg} \mathrm{L}^{-1}, k_{2}$ drops one order of magnitude.

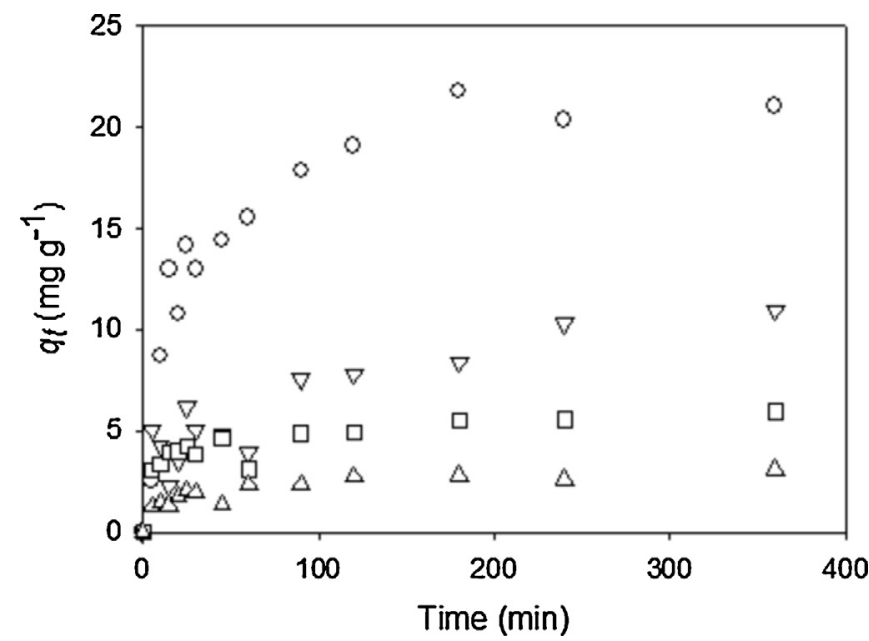

Fig. 5. Adsorption kinetics of SDBS, at different concentrations, on X-50M50T, at $20^{\circ} \mathrm{C} .(\triangle)[\mathrm{SDBS}]=11 \mathrm{mg} \mathrm{L}^{-1},(\square)[\mathrm{SDBS}]=22 \mathrm{mg} \mathrm{L}^{-1},(\nabla)[\mathrm{SDBS}]=44 \mathrm{mg} \mathrm{L}^{-1}$, (o) $[\mathrm{SDBS}]=87 \mathrm{mg} \mathrm{L}^{-1}$.
In order to have a further insight on the mechanism of SDBS adsorption by X-50M50T, adsorption isotherms were determined and these are shown in Fig. 7. The Langmuir model equation (Eq. (5)) fits well the experimental data $\left(R^{2}=0.999\right)$, and the following

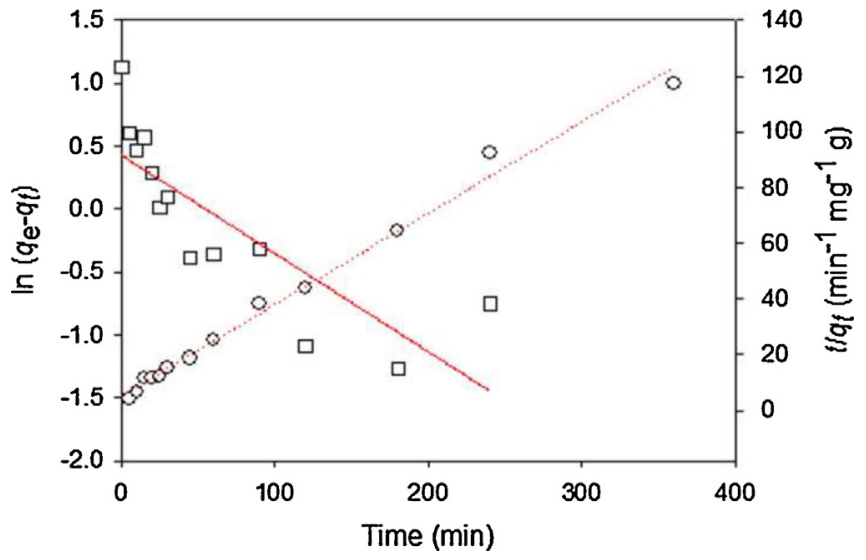

Fig. 6. Representative plot of the fit of linearized forms of pseudo-first (solid line) and pseudo-second (dashed line) order equations to experimental adsorbed amounts of SDBS (with an initial concentration equal to $11 \mathrm{mg} \mathrm{L}^{-1}$ ) by X-50M50T, at $20^{\circ} \mathrm{C}$. 
Table 4

Parameters of Langmuir and Freundlich isotherms and maximum percentage of adsorbate removed.

\begin{tabular}{|c|c|c|c|c|c|c|}
\hline \multirow[t]{2}{*}{ Adsorbate } & \multirow[t]{2}{*}{ Adsorbent } & \multicolumn{3}{|l|}{ Freundlich model } & \multirow[t]{2}{*}{$C_{0}\left(\mathrm{mg} \mathrm{L}^{-1}\right)$} & \multirow[t]{2}{*}{ \% Removal } \\
\hline & & $K_{\mathrm{F}}\left(\mathrm{mgg}^{-1}\left(\mathrm{~L} \mathrm{mg}^{-1}\right)^{1 / n}\right)$ & $1 / n$ & $R^{2}$ & & \\
\hline \multirow{5}{*}{ Phenol } & X-50M50T & $2.72 \times 10^{-2}$ & 1.09 & 0.993 & 100 & 11.2 \\
\hline & A-20M80T & $1.17 \times 10^{-10}$ & 3.87 & 0.988 & 1000 & 5.7 \\
\hline & A-50M50T & $6.47 \times 10^{-7}$ & 2.74 & 0.988 & 1000 & 13.2 \\
\hline & A-80M20T & $3.06 \times 10^{-2}$ & 1.08 & 0.989 & 50 & 11.1 \\
\hline & A-50M50T-CD & $1.16 \times 10^{-4}$ & 1.89 & 0.995 & 1000 & 8.8 \\
\hline \multirow{5}{*}{ p-Cresol } & X-50M50T & $4.30 \times 10^{-3}$ & 1.42 & 0.938 & 10 & 22.1 \\
\hline & A-20M80T & $1.29 \times 10^{-2}$ & 1.02 & 0.921 & 300 & 4.6 \\
\hline & A-50M50T & $2.81 \times 10^{-2}$ & 1.16 & 0.992 & 1000 & 14.3 \\
\hline & A-80M20T & $1.94 \times 10^{-1}$ & 0.88 & 0.998 & 200 & 18.3 \\
\hline & A-50M50T-CD & $1.84 \times 10^{-1}$ & 0.68 & 0.886 & 50 & 7.8 \\
\hline \multirow{5}{*}{ 4-Chloro-phenol } & X-50M50T & $5.24 \times 10^{-2}$ & 1.07 & 0.977 & 10 & 66.4 \\
\hline & A-20M80T & $7.69 \times 10^{-1}$ & 0.43 & 0.751 & 50 & 15.5 \\
\hline & A-50M50T & $1.36 \times 10^{1}$ & 0.32 & 0.919 & 10 & 65.7 \\
\hline & A-80M20T & $30.0 \times 10^{-1}$ & 0.48 & 0.989 & 50 & 46.4 \\
\hline & A-50M50T-CD & $26.0 \times 10^{-1}$ & 0.68 & 0.986 & 200 & 58.5 \\
\hline \multirow[t]{2}{*}{ Adsorbate } & \multirow[t]{2}{*}{ Adsorbent } & \multicolumn{3}{|c|}{ Langmuir model } & & \\
\hline & & \multicolumn{2}{|c|}{$K_{\mathrm{L}}\left(\mathrm{L} \mathrm{mg}^{-1}\right)$} & \multicolumn{2}{|c|}{$q_{\max }\left(\mathrm{mg} \mathrm{g}^{-1}\right)$} & $R^{2}$ \\
\hline 4-Chloro-phenol & A-50M50T & \multicolumn{2}{|c|}{$1.44 \times 10^{-2}$} & \multicolumn{2}{|c|}{117.8} & 0.985 \\
\hline
\end{tabular}

fitting parameters were obtained: $K=4.63 \times 10^{-4} \mathrm{~L} \mathrm{mg}^{-1}$ and $q_{\max }=1029 \mathrm{mg} \mathrm{g}^{-1}$. The empirical Freundlich equation does not fit so well to experimental data $\left(R^{2}=0.992\right)$, leading to $K_{\mathrm{F}}=2.108$ $\left(\mathrm{mg} \mathrm{g}^{-1}\left(\mathrm{~L} \mathrm{mg}^{-1}\right)^{1 / n}\right)$ and $1 / n=0.716$; a $n$ value just slightly higher than 1 also confirms that the adsorption of SDBS on the xerogel is modest.

The free energy of adsorption, $\Delta G^{0}$ ads, of SDBS onto the xerogel can be computed from the equation:

$\Delta G_{\text {ads }}^{0}=-R T \ln \left(K_{0}\right)$

where $R$ is the gas constant, $T$ (=293.15 K) is the absolute temperature and $K_{0}=1 / K$ [37], and is equal to $-18.7 \mathrm{~kJ} / \mathrm{mol}$. This value suggests that hydrophobic interactions, between the surfactant and the xerogel, play a major role on the interaction mechanism. The analysis of fitting parameters of Langmuir equation also shows that the xerogel has a significant maximum capacity of SDBS adsorption.

Looking to the dependence of the percentage of SDBS removal on the initial concentration of SDBS, we can observe a reduction of the removal percentage from 57 to $43 \%$ when the concentration of SDBS increases from 11 to $348 \mathrm{mg} \mathrm{L}^{-1}$ (pre-micelle concentrations), respectively. Then, the SDBS removal percentage level off

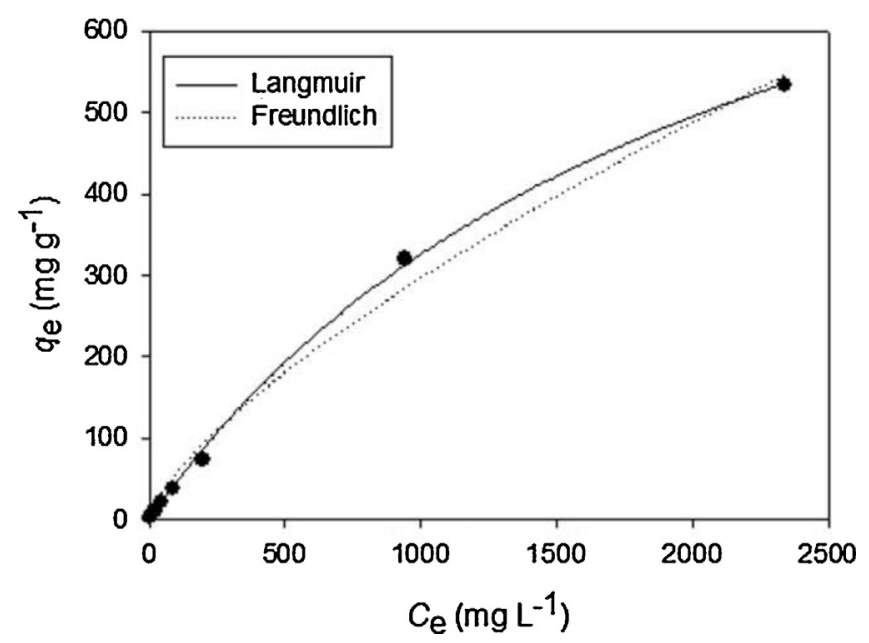

Fig. 7. Adsorption isotherms for $\mathrm{X}-50 \mathrm{M} 50 \mathrm{~T} / \mathrm{SDBS}$ system, at $20^{\circ} \mathrm{C}$. for concentrations above the $\mathrm{CMC}$ (e.g., for $C_{0}=1742 \mathrm{mg} \mathrm{L}^{-1}$ the removal percentage is equal to $40.4 \%$ ). By comparing the SDBS free energy of micellization $\left(-32.2 \mathrm{~kJ} / \mathrm{mol}\right.$ [38]) with $\Delta G^{0}{ }_{a d s}$, it can be concluded that unimer-unimer interaction is stronger than unimer-xerogel and, consequently, adsorption has no effect on the micellization process.

\subsection{Adsorption of phenolic contaminants into aerogels/xerogel}

The adsorption equilibrium data of four aerogels (A-20M80T, A-50M50T, A-80M20T and A-50M50T-CD) and one xerogel (X50M50T) for the selected toxic phenolic compounds are shown in Figs. 8-10. From global results, it can be seen that the tested materials exhibit different adsorption capacities for phenol, $p$-cresol and 4-chlorofenol depending on their level of hydrophobicity determined by amounts of MTMS and TMOS precursors incorporated in the synthesis process.

The unfavourable nature of most adsorption isotherms obtained for phenol and p-cresol, as illustrated in Figs. 8 and 9, suggests limited affinity between these contaminants and the studied

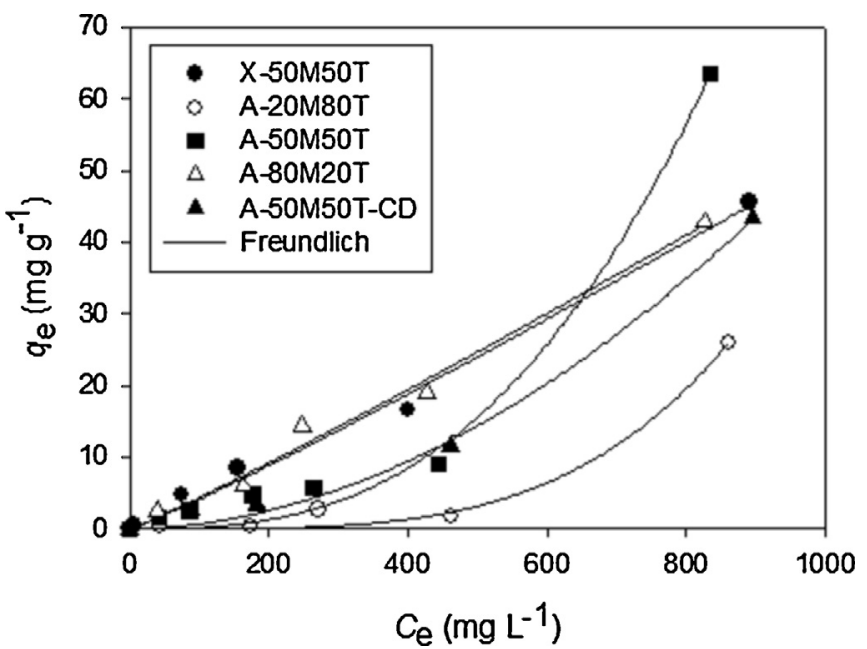

Fig. 8. Experimental and calculated equilibrium data for adsorption of phenol on aerogels and xerogel adsorbents. 


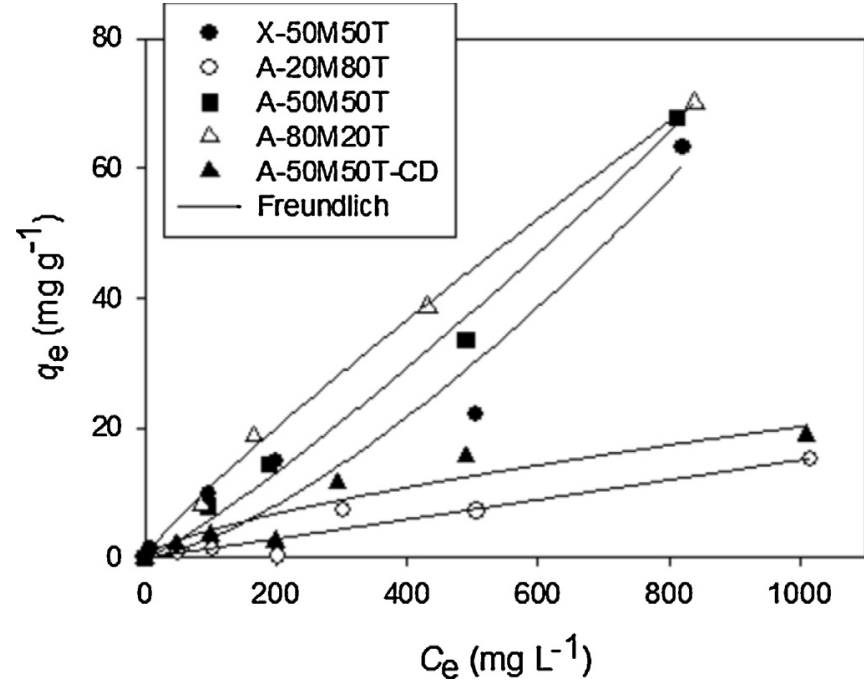

Fig. 9. Experimental and calculated equilibrium data for adsorption of $p$-cresol on aerogels and xerogel adsorbents.

aerogels/xerogel, mainly for low concentrations. Fig. 10 shows that 4-chlorofenol is adsorbed to a greater extent than the other compounds, and the equilibrium data is characterized by favourable isotherms. This should be attributed to the stronger hydrophobic character of the adsorbate that plays an important role in the amount adsorbed from aqueous solutions. The modification of the aerogel with $\beta$-CD (A-50M50T-CD) was successful in the case of 4chlorofenol (see Fig. 10) likely because its hydrophobic interactions with the $\beta$-CD cavities in the adsorbent were enhanced. Moreover, it is also worth mentioning that higher adsorption capacity is observed for the aerogel-type adsorbents than for the xerogel, for all the adsorbates. The higher amount of mesopores in the aerogels when compared to the xerogel seems to play an important role in the adsorption process. Effectively, the very fine porous structure of the xerogel (Section 3.1.2) may hinder the diffusion of the phenolic compounds in the solid matrix.

The parameter values estimated by fitting the equilibrium models to the experimental data are listed in Table 4. It should be noted that the Langmuir model only fits well the data corresponding to the system A-50M50T/4-chlorophenol. Therefore, the Freundlich model is the most suitable, which has been applied in numerous cases involving the removal of organic contaminants from aqueous solutions since it has the ability to describe the adsorption in heterogeneous surfaces. The correlation coefficients $\left(R^{2}\right)$ shown in

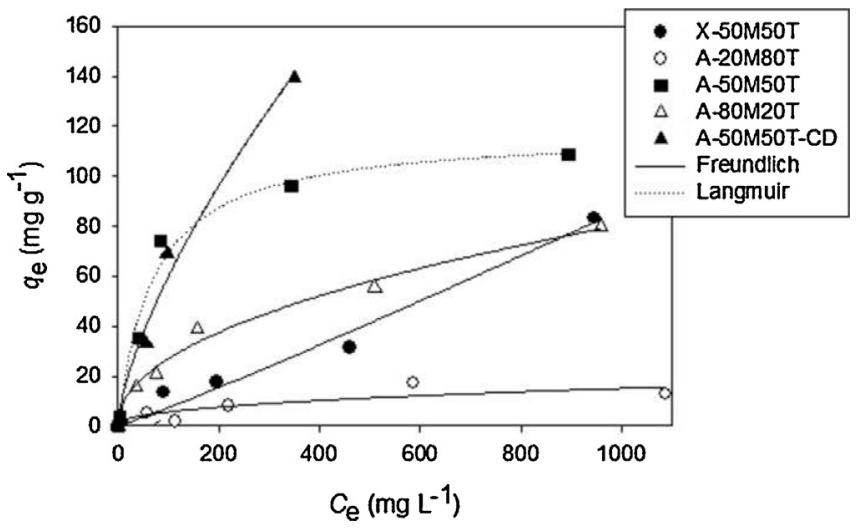

Fig. 10. Experimental and calculated equilibrium data for adsorption of 4chlorophenol on aerogels and xerogel adsorbents. the table indicate that the experimental and predicted results are in good agreement in most cases.

With respect to the maximum percentage of adsorbate removed from the aqueous solution, Table 4 shows the initial concentrations, $C_{0}$, for which the best results were observed for each pollutant. In the case of phenol, the percentage of removal was low for all the tested materials, but the adsorbent A-50M50T revealed to have the best performance. Contrarily to our expectations, the addition of $\beta$-CD does not improve the performance of the aerogel A-50M50T. Nevertheless, the percentages of phenol removed in our investigation are higher than in other studies reported in the literature $[8,16]$, where for a solution with initial concentration of $1000 \mathrm{mg} \mathrm{L}^{-1}$, the equilibrium adsorption was around $10 \mathrm{mg} \mathrm{g}^{-1}$ and the corresponding percentage of removal was close to $4 \%$. Regarding $p$-cresol, the percentage of removal improves slightly for A-50M50T when compared to phenol. However, also for this compound further improvement in the adsorbents will be required. Finally, the best results were obtained for 4-chlorophenol, since removals higher than $60 \%$ were observed. As mentioned before, it should be noted that the addition of $\beta$-CD seems to be an interesting route to improve the removal of this phenolic compound.

\section{Conclusions}

The silica-based aerogels and xerogels prepared in this work exhibit mesoporous structures with high surface area and tailored levels of hydrophobicity/hydrophilicity. This last feature is achieved by combining different amounts of methyltrimethoxysilane and tetramethylorthosilicate co-precursors, as well as by functionalizing the silica aerogels with $\beta$-cyclodextrin macrocycle.

The xerogel with intermediate wetting behaviour shows good removal efficiency for SDBS and a pseudo-second order adsorption kinetics. In this case the adsorption is probably characterized by hydrophobic interactions and the monolayer formation may be the rate-limiting step. When studying the aerogels as adsorbents for several phenolic compounds - phenol, $p$-cresol and 4-clorophenol, the hydrophobic adsorbents show higher performances for the adsorbates with higher partition coefficient octanol/water, with favourable isotherms, showing that the hydrophobic interactions play an important role in the adsorption process. In particular, the aerogel modified with $\beta$-cyclodextrin leads to high adsorption capacity of 4-chlorophenol, the most hydrophobic adsorbate tested, being this a result of the high hydrophobic character of the $\beta$-cyclodextrin cavity.

\section{Acknowledgements}

This work was developed under the QREN project No. 34078, designated by "CleanOlGel - Functionalization of silica-based aerogels for treatment of wastewater with phenolic compounds", by the consortium Active Aerogels/UC/Ventilaqua, funded by ADI, through the Promotion of Research and Technological Development System of QREN.

\section{References}

[1] G. Busca, S. Berardinelli, C. Resini, L. Arrighi, Technologies for the removal of phenol from fluid streams: a short review of recent developments, J. Hazard. Mater. 160 (2008) 265-288.

[2] A. Dąbrowski, P. Podkościelny, Z. Hubicki, M. Barczak, Adsorption of phenolic compounds by activated carbon - a critical review, Chemosphere 58 (2005) 1049-1070.

[3] J. Michałowicz, W. Duda, Phenols - sources and toxicity, Pol. J. Environ. Stud. 16 (2007) 347-362.

[4] M.N. Perdigoto, R.C. Martins, N. Rocha, M.J. Quina, L. Gando-Ferreira, R. Patrício, L. Durães, Application of hydrophobic silica-based aerogels and xerogels for removal of toxic organic compounds from aqueous solutions, J. Colloid Interface Sci. 380 (2012) 134-140. 
[5] S. Štandeker, Z. Novak, Ž. Knez, Adsorption of toxic organic compounds from water with hydrophobic silica aerogels, J. Colloid Interface Sci. 310 (2007) 362-368.

[6] M.A. Aegerter, N. Leventis, M.M. Koebel, Aerogels Handbook, 1st ed., Springer, New York, 2011.

[7] G. Qin, Y. Yao, W. Wei, T. Zhang, Preparation of hydrophobic granular silica aerogels and adsorption of phenol from water, Appl. Surf. Sci. 280 (2013) 806-811.

[8] F. An, B. Gao, X. Feng, Adsorption mechanism and property of novel composite material PMAA/SiO 2 towards phenol, Chem. Eng. J. 153 (2009) 108-113.

[9] Z. Wu, I.-S. Ahn, C.-H. Lee, J.-H. Kim, Y.G. Shul, K. Lee, Enhancing the organic dye adsorption on porous xerogels, Colloids Surf. A 240 (2004) 157-164.

[10] Z. Wu, H. Joo, I.-S. Ahn, S. Haam, J.-H. Kim, K. Lee, Organic dye adsorption on mesoporous hybrid gels, Chem. Eng. J. 102 (2004) 277-282.

[11] Z. Wu, L. You, H. Xiang, Y. Jiang, Comparison of dye adsorption by mesoporous hybrid gels: understanding the interactions between dyes and gel surfaces, J. Colloid Interface Sci. 303 (2006) 346-352.

[12] A. Soleimani-Dorcheh, M.H. Abbasi, Silica aerogel; synthesis, properties and characterization, J. Mater. Process. Technol. 199 (2008) 10-26.

[13] L. You, Z. Wu, T. Kim, K. Lee, Kinetics and thermodynamics of bromophenol blue adsorption by a mesoporous hybrid gel derived from tetraethoxysilane and bis(trimethoxysilyl)hexane, J. Colloid Interface Sci. 300 (2006) 526-535.

[14] K. Haghbeen, R.L. Legge, Adsorption of phenolic compounds on some hybrid xerogels, Chem. Eng. J. 150 (2009) 1-7.

[15] F. An, B. Gao, Adsorption of phenol on a novel adsorption material PEI/SiO 2 , J. Hazard. Mater. 152 (2008) 1186-1191.

[16] F. An, B. Gao, X. Feng, Adsorption and recognizing ability of molecular imprinted polymer MIP-PEI/SiO 2 towards phenol, J. Hazard. Mater. 157 (2008) 286-292.

[17] H. Faraji, S.W. Husain, M. Helalizadeh, $\beta$-Cyclodextrin-bonded silica particles as novel sorbent for stir bar sorptive extraction of phenolic compounds, J. Chromatogr. Sci. 49 (2011) 482-487.

[18] H. Faraji, S.W. Husain, M. Helalizadeh, Determination of phenolic compounds in environmental water samples after solid-phase extraction with $\beta$-cyclodextrin-bonded silica particles coupled with a novel liquid-phase microextraction followed by gas chromatography-mass spectrometry, J. Sep. Sci. 35 (2012) 107-113.

[19] M. Anbia, M. Lashgari, Synthesis of amino-modified ordered mesoporous silica as a new nano sorbent for the removal of chlorophenols from aqueous media, Chem. Eng. J. 150 (2009) 555-560.

[20] M. Anbia, S. Amirmahmoodi, Adsorption of phenolic compounds from aqueous solutions using functionalized SBA-15 as a nano-sorbent, Sci. Iran. Trans. C 18 (2011) 446-452.

[21] L. Durães, M. Ochoa, N. Rocha, R. Patrício, N. Duarte, V. Redondo, A. Portugal, Effect of the drying conditions on the microstruture of silica-based xerogels and aerogels, J. Nanosci. Nanotechnol. 12 (2012) 1-7.
[22] L. Durães, M. Ochoa, A. Portugal, N. Duarte, J.P. Dias, N. Rocha, J. Hernandez, Tailored silica-based xerogels and aerogels for insulation in space environments, Adv. Sci. Technol. 63 (2010) 41-46.

[23] M. Ochoa, L. Durães, A.M. Beja, A. Portugal, Study of the suitability of silica-based xerogels synthesized using ethyltrimethoxysilane and/or methyltrimethoxysilane precursors for aerospace applications, J. Sol-Gel Sci. Technol. 61 (2012) $151-160$.

[24] Sigma-Aldrich, Material Safety Data Sheets, 2013.

[25] D.R. Lide (Ed.), CRC Handbook of Chemistry and Physics, 85th ed., CRC Press, Boca Raton, 2005.

[26] Product properties test guidelines: OPPTS 830.7570: partition coefficient (noctanol/water), estimation by liquid chromatography, EPA 712-C-96-040, US EPA (1996).

[27] C. Hansch, A. Leo, Substituent Constants for Correlation Analysis in Chemistry and Biology, John Wiley and Sons, New York, 1979.

[28] B. Jonsson, B. Lindman, K. Holmberg, B. Kronberg, Surfactants and Polymers in Aqueous Solution, John Wiley \& Sons, Chichester, 1998.

[29] S. Lagergren, Zur theorie der sogenannten adsorption gelöster stoff, K. Sven. Vetenskapsak. Handl. 24 (4) (1989) 1-39.

[30] Y.S. Ho, G. McKay, Adsorption of dye from aqueous solution by peat, Chem. Eng. J. 70 (2) (1998) 115-124.

[31] S.R. Taffarel, J. Rubio, On the removal of $\mathrm{Mn}^{2+}$ ions by adsorption onto natural and activated Chilean zeolites, Miner. Eng. 22 (4) (2009) 336-343.

[32] R. Al-Oweini, H. El-Rassy, Synthesis and characterization by FTIR spectroscopy of silica aerogels prepared using several $\mathrm{Si}(\mathrm{OR})_{4}$ and $\mathrm{R}^{\prime \prime} \mathrm{Si}\left(\mathrm{OR}^{\prime}\right)_{3}$, J. Mol. Struct. 354 (2009) 140-145.

[33] H. Becker, W. Berger, G. Domschke, E. Fanghänel, J. Faust, M. Fischer, F. Gentz, K. Gewald, R. Gluch, R. Mayer, K. Müller, D. Pavel, H. Schmidt, K. Schollberg, K. Schwetlick, E. Seiler, G. Zeppenfeld, Organikum, 2nd ed., Calouste Gulbenkian Foundation, Lisbon, 1997.

[34] S.R. Taffarel, J. Rubio, Adsorption of sodium dodecyl benzene sulfonate from aqueous solution using a modified natural zeolite with CTAB, Miner. Eng. 23 (2010) 771-779.

[35] Y.-S. Ho, Review of second-order models for adsorption systems, J. Hazard. Mater. B 136 (2006) 681-689.

[36] Y.-S. Ho, Pseudo-isotherms using a second order kinetic expression constant, Adsorption 10 (2004) 151-158.

[37] X. Huang, N.-Y. Gao, Q.-L- Zhang, Thermodynamics and kinetics of cadmium adsorption onto oxidized granular activated carbon, J. Environ. Sci. 19 (2007) 1287-1292.

[38] A.J.M. Valente, J.J. López Cascales, A.J. Fernández Romero, Thermodynamic analysis of unimer-micelle and sphere-to-rod micellar transitions of aqueous solutions of sodium dodecylbenzenesulfonate, J. Chem. Thermodyn. 77 (2014) 54-62. 